\title{
How to manage mixed secondary forest in a sustainable way?
}

\author{
Lihu Dong ${ }^{1} \cdot$ Xingji Jin ${ }^{1} \cdot$ Timo Pukkala $^{1,2} \mathbb{D} \cdot$ Fengri Li ${ }^{1} \cdot$ Zhaogang Liu $^{1}$
}

Received: 2 January 2019 / Revised: 26 March 2019 / Accepted: 13 April 2019 / Published online: 15 May 2019

(c) The Author(s) 2019

\begin{abstract}
Secondary mixed forests of larch and birch are common in the mountainous areas of north-eastern China. In the Daxing'an Mountain of Heilongjiang Province, the larch species of this type of forest is Larix gmelinii Rupr. and the birch species is Betula platyphylla Suk. Science-based information on the optimal sustainable management of these forests is largely missing. Since the forests serve multiple functions, including soil protection, carbon sequestration and maintenance of habitats, only continuous cover forestry is regarded acceptable. This study optimized a sequence of transformation cuttings of mixed secondary forests of larch and birch to sustainable steady-state uneven-aged structure. The optimization problem was formulated in such a way that the species composition of the steady-state forest was also sustainable. A reference management scenario was obtained by letting the stands grow for 100 years without any cuttings. The results showed that the no-management option leads to low rate of regeneration and ingrowth, and the stands do not develop towards typical uneven-aged structures. Maximizing net present value without any constraints leads to heavy cuttings, making these schedules unacceptable from the soil protection and carbon storing point of views. Schedules that were evaluated as the most recommendable were obtained by adding a minimum basal area constraint to the problem formulation, and maximizing species and size diversity of the steady-state forest simultaneously with net present value.
\end{abstract}

Keywords Equilibrium endpoint problem · Transformation cuttings · Steady-state forest · Particle swarm optimization · Mixed forest $\cdot$ Multifunctional forestry $\cdot$ Continuous cover forestry $\cdot$ Larix gmelinii $\cdot$ Betula platyphylla

\section{Introduction}

Most naturally regenerated forests of China are secondary forests. The area of secondary forest is 138 million ha, which is $59 \%$ of the total forest area of China. In the Heilongjiang Province (Northeast China), the total forest area is 19.62 million ha, of which tree plantations cover 2.47 million ha (13\%). The remaining $87 \%$ are mainly secondary forests (State Forestry Administration 2014; State Forestry Bureau 2014). The structure of these forests is often closer

Communicated by Lluís Coll.

Timo Pukkala

timo.pukkala@uef.fi

1 Key Laboratory of Sustainable Forest Ecosystem Management - Ministry of Education, School of Forestry, Northeast Forestry University, Harbin 150040, Heilongjiang, People's Republic of China

2 University of Eastern Finland, P.O. Box 111, 80101 Joensuu, Finland to even-aged than uneven-aged since most secondary forests are naturally regenerated on clear-felled or heavily cut sites.

Naturally regenerated secondary forests cannot be cut in Heilongjiang at the moment (2019). Before the cutting ban, the forest policy of China was to manage natural forests using selective fellings and continuous cover forestry (State Forestry Bureau 2005). However, this policy was not always followed, and the cutting practices were often unsustainable and ecologically unacceptable, leading to too low densities of post-cutting stands.

The current logging ban is only partly because of undesired state of many secondary forests. Another reason is lacking knowledge on sustainable management of these forests. There is very little research on the continuous cover management of Chinese forests and hardly any research on the conversion of secondary forests into sustainable uneven-sized structures. The cutting ban might be withdrawn when new information about sustainable continuous cover management of naturally regenerated secondary forests becomes available.

The Daxing' an Mountain is a region in Heilongiiang with plenty of secondary forest, many of which are mixtures of 
larch (Larix gmelinii Rupr.) and birch (Betula platyphylla Suk.). The total area of larch and birch forests is 6.6 million ha in Daxing' an Mountain, and 4.8 million ha of this area is mixed larch and birch secondary forest. Previous research on these forests has focused on the recovery of the forests after fire (Shi et al. 2000; Sun et al. 2009), modelling stem taper, biomass, or diameter distribution (Jiang et al. 2016; Dong and Li 2016; Liu et al. 2014), water conservation and hydrological issues ( $\mathrm{Li}$ et al. 2014; Jiang 2008), or harvest scheduling at the landscape level (Dong et al. 2015a, 2018).

The management objectives of the natural forests in China include soil protection, biodiversity maintenance and carbon sequestration (State Development Planning Commission and State Forestry Bureau 2010). In mountainous areas, timber production and economic profit can be regarded as secondary objectives. Wood production or economic profit can be pursued under strict ecological constraints. The ideal structure of larch-birch mixtures is a multi-layered uneven-sized forest, which is able to maintain this structure continuously.

Mixed forests with several canopy layers are considered the most resilient (Knoke et al. 2008; Thompson et al. 2009; Jactel et al. 2017). Resiliency refers to the capacity of the forest to maintain its ecological services in changing conditions and recover quickly from disturbances such as wildfire, wind damage, diseases and pest outbreaks. Since these disturbances kill tree species and canopy layers selectively, it is likely that at least part of trees would survive if the stand consists of several species in several canopy layers. Recognizing the importance of species mixtures, Bettinger and Tang (2015) maximized the mingling index of an unevenaged oak-hickory forest in Eastern United States subject to minimum basal area and harvest volume targets.

Stands with high tree species and tree size diversity also have a high overall diversity since different tree species and sizes offer habitats for different species. The presence of several tree species and timber assortments also decreases the risk against economic fluctuations (Knoke and Wurm 2006). A mixture of broadleaves in a conifer stand makes the stand less vulnerable to wind damage (Lüpke and Spellmann 1999; Knoke et al. 2008).

There are several earlier studies on management optimization of uneven-aged stands and on the optimal transformation of even-sized forests into sustainable uneven-aged structures (e.g. Adams and Ek 1974; Haight and Getz 1987; Haight and Monserud 1990a, b; Wikström 2000; Bettinger et al. 2005; Bayat et al. 2013; Pukkala et al. 2014; Rämö and Tahvonen 2014, 2015). However, few of these studies can be applied to the secondary forests of China. There are few optimization studies on sustainable uneven-aged management of mixed stands conducted under the constraint that the species mixture must also be sustainable.

Most of the earlier optimization studies on uneven-aged management maximize economic profitability (e.g. Haight et al. 1985; Rämö and Tahvonen 2014) or timber production (e.g. Rämö and Tahvonen 2015). Some of the earlier studies include constraints that are related to the ecological quality of the stand, such as the requirement for continuous presence of large trees (e.g. Bettinger et al. 2005; Trasobares and Pukkala 2005).

Four types of problem formulations can be encountered in studies that optimize uneven-aged management at the stand level. The simplest formulations optimize the steady-state diameter distribution and harvesting, without optimizing the transformation cuttings of a specific initial stand (Sanchez Orois et al. 2004; Trasobares and Pukkala 2005; Buongiorno et al. 2012). Another approach, so-called fixed endpoint problem, sets a target distribution for the steady-state forest and optimizes transformation cuttings so that they lead to the target distribution (Adams and Ek 1974; Buongiorno, 2001).

The third category of studies simultaneously optimizes the transformation cuttings and the steady-state diameter distribution (Haight and Monserud 1990a, b; Rämö and Tahvonen 2014, 2015; Pukkala 2015). This formulation is referred to as the equilibrium endpoint problem. The fourth formulation sets no steady-state targets (Wikström 2000); a long sequence of cuttings is optimized without the requirement that the forest must reach an equilibrium diameter distribution. This approach eliminates the need for the use of diameter classes to check sustainability and involves no fixed cutting cycles (Wikström 2000).

In many cases, a steady-state forest is desirable since knowing its structure makes it possible to assess the longterm sustainability of the management system. Therefore, using equilibrium endpoint formulations with a long transformation period may be regarded as a good approach in most cases. Setting a certain fixed steady-state forest structure as a target may also be justified for ecological reasons (Bettinger et al. 2005; Bettinger and Tang 2015). However, ecological objectives may be included also in equilibrium endpoint problems, either via constraints or using an objective function that includes multiple objectives.

The first study that optimized the management of mixed uneven-aged forests was that of Adams and Ek (1974). They first found the steady-state diameter distribution and then optimized cuttings that would lead to the specified steadystate stand structure. Haight and Getz (1987) optimized the management of mixed stands of Abies magnifica and Abies concolor using the equilibrium endpoint problem formulation. Haight and Monserud (1990a, b) optimized the management of stands consisting of seven tree species grouped into three groups. They used the same equilibrium endpoint model specification as Haight and Getz (1987), with a 160year conversion horizon.

Buongiorno et al. (2012) optimized the steady-state structure of mixed Nordic forests in multi-objective uneven-aged management. The objectives considered were economic 
returns, carbon sequestration and the diversity of tree species and tree size. Species and size diversity were described using relative Shannon index (Shannon index divided by its maximum theoretical value in a particular stand).

Rämö and Tahvonen (2015) were the first who optimized the management of uneven-aged species mixtures in the Nordic countries using the equilibrium endpoint model specification. When volume yield was maximized, the optimal steady state was a nearly pure Norway spruce stand. When the net present value of stumpage revenues was maximized, the steady-state stands were either nearly pure Norway spruce stands or mixtures of Norway spruce and birch. Rämö and Tahvonen (2015) used a transition matrix model and a fixed cutting interval.

Sterba (2004) concluded that the optimal steady-state distribution does not guarantee that the stand will remain as a mixed stand. An equilibrium in stem number does not necessarily mean a stable species distribution. Therefore, there is a need to conduct optimizations with a constraint that all species separately are in the steady state.

The aim of this study was to find the optimal steady-state management and stand structure of larch and birch mixtures in Daxing' an Mountain under ecology-related constraints. In addition, the sequence of cuttings that transformed a secondary forest into sustainable steady-state structure was optimized. The ecological constraints set the minimum basal area of the post-cutting residual stand. In addition, it was required that the diameter distributions of both species represented a steady-state structure, which guaranteed the sustainability of the species mixture.

\section{Materials and methods}

\section{Study area and sample plots}

The study site is located in the Daxing' an Mountain in Heilongjiang Province $\left(52^{\circ} 30^{\prime} 0^{\prime \prime} \mathrm{N}, 123^{\circ} 54^{\prime} 0^{\prime \prime} \mathrm{E}\right)$. The mean annual temperature ranges from -2.6 to $-1{ }^{\circ} \mathrm{C}$. Winters are cold, the average lowest temperature of the year being $-50{ }^{\circ} \mathrm{C}$. The mean temperature of the coldest month (January) is about $-22^{\circ} \mathrm{C}$, and the mean temperature of the warmest month (July) is around $20{ }^{\circ} \mathrm{C}$. The annual precipitation is $530-700 \mathrm{~mm}$. The frost-free period lasts for $80-110$ days per year. The soil type is mostly "brown conifer forest soil".

The School of Forestry of the Northeast Forestry University of China has measured several sample plots of $50 \mathrm{~m}$ by $40 \mathrm{~m}$ in the mixed secondary forests of larch and birch in the Daxing' an Mountain. The dbh, height and coordinates of every tree have been measured. For the current study, we selected four plots so that two plots had nearly equal proportions of larch and birch, one being larch-dominated and one birch-dominated (Table 1).

The plots were used as the starting point of simulation and optimization, which aimed at finding the optimal sequence of transformation cuttings simultaneously with the optimal structure and cutting interval of a steady-state forest. Individual-tree growth and survival models developed earlier at the Northeast Forestry University of Harbin were used in simulation. In addition to the models for diameter increment and survival, simulation employed models for ingrowth, tree height, stem taper and biomass. Stand development was simulated in 5-year time steps because the models for diameter
Table 1 Information on the sample plots

\begin{tabular}{lllll}
\hline Variable & Plot 58(7) & Plot 38(11) & Plot 38(18) & Plot 96(2) \\
\hline No. of trees per hectare & 2205 & 1950 & 1235 & 1905 \\
Larch & 575 & 1075 & 750 & 1500 \\
Birch & 1630 & 875 & 485 & 405 \\
Stand basal area $\left(\mathrm{m}^{2}\right.$ ha $\left.^{-1}\right)$ & 16 & 16 & 19 & 22 \\
Mean diameter $(\mathrm{cm})$ & 9.7 & 10.2 & 13.8 & 12.2 \\
Larch & 8.4 & 12.1 & 17.5 & 13.7 \\
Birch & 12.9 & 9.1 & 12.8 & 9.3 \\
Biomass (ton ha & -1 & 81 & 109 & 118 \\
Stems & 81 & 52 & 69 & 76 \\
Branches & 51 & 7 & 10 & 9 \\
Foliage & 8 & 2 & 3 & 3 \\
Roots & 2 & 20 & 27 & 30 \\
Species diversity & 19 & 0.688 & 0.670 & 0.517 \\
Size diversity & 0.574 & 0.558 & 0.572 & 0.592 \\
\hline
\end{tabular}

${ }^{\mathrm{a}}$ Shannon index

${ }^{\mathrm{b}}$ Gini index 
increment, survival and increment were fitted for 5-year time step. Since most of the models that we used in simulation have not been published in international scientific journals, they are shortly described in "Appendix 1" of this study.

The ingrowth model predicts the number of trees that pass the 5-cm limit during a 5-year period. Therefore, the development of trees larger than $5 \mathrm{~cm}$ was simulated in this study. The lower limit of the smallest diameter class was also $5 \mathrm{~cm}$. The taper models were used to calculate the volumes of different timber assortments of harvested trees (Table 2). The volumes were multiplied by the stumpage prices of the assortments, to obtain the net income from the cutting.

\section{Optimizations}

The first part of the analysis consisted of simulating the stand development for 100 years, using the models for diameter increment, survival and ingrowth. Biomass models were used to calculate the total living biomass of the stand (belowground and aboveground). Also the carbon stock was calculated, but it is not reported separately since it is always almost exactly $50 \%$ of the total dry mass of living biomass.

Then, a sequence of cuttings that converted the stand to a sustainable steady-state stand structure was optimized. The time points and harvest intensities of five transformation cuttings were optimized. It was assumed that subsequent steady-state cuttings reduce the frequencies of trees in different diameter classes to the same level as obtained in the last transformation cutting. It was assumed that this cutting is repeated to infinity using a certain cutting cycle (cutting interval), which was also optimized.

The development of the post-cutting stand after the fifth transformation cutting was simulated for one cutting cycle to check that the post-cutting stand represented a sustainable steady-state structure. At the end of this additional cycle, a cutting was simulated by reducing the frequencies of trees in different diameter classes to the same level as in the postcutting stand after the last (5th) transformation cutting. This 6th cutting was not optimized as the number of remaining trees in different diameter classes was the same as in previous cutting.
If it was not possible to reach the same post-thinning diameter distribution as obtained in the last optimized cutting, the steady-state management was not sustainable and the solution was not accepted. This happened when the number of trees was, in some diameter classes, smaller at the end of the cutting cycle (after growing, before cutting) than in the beginning of the cutting cycle (after the 5th transformation cutting). The main reason for this situation was insufficient ingrowth; the number of trees that grew away from the smallest diameter classes was larger than the number of ingrowth trees that entered these classes. The sustainability of the steady-state forest was evaluated using 4-cm-diameter classes.

The net present value (NPV) of the cutting schedule (including transformation cuttings and steady-state management) was calculated from the removals of timber assortments in the transformation cuttings and in the cutting of the steady-state forest. To calculate NPV to infinity, it was assumed that the steady-state cutting cycle was repeated to infinity. The following formulas were used:

$\mathrm{NPV}_{\text {trans }}=\sum_{j=1}^{J} \frac{R_{j}}{(1+r)^{T_{j}}}$

$\mathrm{NPV}_{\text {steady }}=\frac{R_{\mathrm{cc}}}{(1+r)^{T_{\mathrm{cc}}}-1}$

$\mathrm{NPV}_{\text {total }}=\mathrm{NPV}_{\text {trans }}+\frac{\mathrm{NPV}_{\text {steady }}}{(1+r)^{T_{J}}}$

where NPV trans is the NPV and $J$ is the number of transformation cuttings, $R_{j}$ is the net income (return), $T_{j}$ the year of cutting $j$ and $r$ the is discount rate ( $r=0.02$ with a $2 \%$ discount rate). $\mathrm{NPV}_{\text {steady }}$ is the NPV of the steady-state management, discounted to the year of the last transformation cutting $\left(T_{J}\right), R_{\mathrm{cc}}$ is the net income obtained from one cutting of steady-state management and $T_{\mathrm{cc}}$ is the length of the cutting cycle in steady-state management. The third formula gives the total NPV of the cutting cycle (from the first simulation year to infinity). The NPV of the steady-state management

Table 2 Minimum top diameter, minimum log length and stumpage price of different timber assortments

\begin{tabular}{|c|c|c|c|c|c|c|}
\hline \multirow[t]{2}{*}{ Assortment } & \multicolumn{3}{|l|}{ Larch } & \multicolumn{3}{|l|}{ Birch } \\
\hline & Diameter $(\mathrm{cm})$ & Length (m) & Price $\left(\mathrm{CNY} / \mathrm{m}^{3}\right)$ & Diameter $(\mathrm{cm})$ & Length (m) & Price $\left(\mathrm{RMB} / \mathrm{m}^{3}\right)$ \\
\hline Large log & 24 & 3 & 900 & 18 & 3 & 900 \\
\hline Medium log & 16 & 2 & 800 & 14 & 2 & 750 \\
\hline Small log & 11 & 2 & 700 & 10 & 2 & 600 \\
\hline Pole & 4 & 2 & 600 & 6 & 2 & 350 \\
\hline
\end{tabular}

CNY Chinese yuan. In December 2018, 1 CNY was worth of 0.13 euro 
was discounted from year $T_{J}$ to the first simulation year and added to the NPV of the transformation period.

The first set of optimizations optimized five transformation cuttings and the steady-state management by maximizing NPV without any constraints. A 2\% discount rate was used. The purpose was to see whether "normal" economic optimization of CCF management would lead to ecologically acceptable sustainable management.

Since this was not always the case, a second set of optimizations was conducted where the minimum allowed basal area was set to $10 \mathrm{~m}^{2} \mathrm{ha}^{-1}$, and the thinnings were optimized separately for both tree species. The sustainability of the post-cutting stand of the steady-state management was verified separately for larch and birch. These optimizations guaranteed that the steady-state forest structures, proposed by the optimizations, were such that the stands would remain as mixed stands in all subsequent cuttings.

The solutions of all optimizations were evaluated in terms of species and size diversity of the steady-state forest. Species diversity was described with the Shannon index (Pielou 1977) and size diversity by the Gini index (Valbuena et al. 2012).

A third set of optimizations was conducted to see whether the management schedules could be improved, in terms of diversity, by maximizing multi-objective utility function instead of only NPV. The utility function used in the last optimizations was as follows:

$U=w_{1}\left(\mathrm{NPV} / \mathrm{NPV}_{\max }\right)+w_{2}\left(\mathrm{SI} / \mathrm{SI}_{\max }\right)+w_{3}\left(\mathrm{GI}_{/ \mathrm{GI}_{\max }}\right)$

where $U$ is the utility of the management schedule, NPV is its net present value, SI is the average Shannon index during a cutting cycle of steady-state management and GI is the average Gini index of the stand during a cutting cycle. $\mathrm{NPV}_{\max }, \mathrm{SI}_{\max }$ and $\mathrm{GI}_{\max }$ are the maximum possible values of the three objective variables. They were used to convert NPV, SI and GI to relative values, which removed the effect of different units. $\mathrm{NPV}_{\max }$ was obtained from single-objective optimizations, $\mathrm{SI}_{\max }$ was the maximum theoretical value of Shannon index for two-species forest (0.693), and 0.8 was used as $\mathrm{GI}_{\max }$ (Pukkala et al. 2016). The weights of the three objectives were equal $\left(w_{1}=w_{2}=w_{3}=0.333\right)$.

For each cutting, the following decision variables were optimized:

- Number of years to the cutting

- Parameters of the thinning intensity curve

The thinning intensity curve shows the proportion of trees removed from different diameter classes (Jin et al. 2017; Peng et al. 2018).

$\operatorname{TI}(d)=\frac{1}{1+\exp \left(a_{1}\left(a_{2}-d\right)\right)}$ where $\operatorname{TI}(d)$ is the proportion of harvested trees when dbh is $d \mathrm{~cm}$; and $a_{1}$ and $a_{2}$ are parameters (optimized for each cutting). When the same thinning intensity curve was used for both species (the first set of optimizations), the number of optimized variables was three for each transformation cutting (number of years from previous cutting and parameters $a_{1}$ and $a_{2}$ of the thinning intensity curve). When thinnings were optimized separately for the two species, there were five optimized variables per cutting (number of years and two pairs of parameters of the thinning intensity curve). Since the length of the cutting cycle in steady-state management was also optimized, the total number of optimized variables (DS) was DS $=3 \times N_{\mathrm{tc}}+1=16$ (species not optimized separately) or DS $=5 \times N_{\mathrm{tc}}+1=26$ (species optimized separately) where $N_{\mathrm{tc}}$ is the number of transformation cuttings (5 in this study).

The optimization method selected for this study was particle swarm optimization (PSO) implemented as explained in Pukkala (2009). The choice was based on preliminary optimizations with different methods and the study of Jin et al. (2018) who found that differential evolution was usually the best method in stand management optimization problems, but when the number of optimized decision variables increased, PSO seemed to become better than differential evolution. In our current study, the number of optimized variables was high, and therefore, PSO was used. The algorithm of PSO and its use in stand management optimization is described in "Appendix 2".

\section{Results}

\section{Stand development without any management}

When the plots were left to grow for 100 years without any cuttings, the stand biomass (including roots, stems, branches and foliage) increased from the initial 80-120 tons ha ${ }^{-1}$ to about $160-200$ tons $^{-1}$ (Fig. 1). The rate of biomass growth started to decrease after about 60 years. The mean diameter of trees increased from about $10 \mathrm{~cm}$ to $20 \mathrm{~cm}$. The number of trees decreased substantially because ingrowth was clearly smaller than mortality.

The stands did not develop into multi-layered unevenaged stands (Fig. 2), and species and size diversity sometimes decreased (Fig. 1). Species diversity increased in the birch-dominated stand (58(7)) but decreased in the larchdominated stand (96(2)), suggesting that stands would slowly develop towards pure larch stands or at least towards a clear dominance of larch. The larch-dominated plot (96(2)) developed into almost pure larch stand. Although the size diversity (Gini index) did not change much during the 100-year simulation, the size structure of the stands changed greatly (Fig. 2). The typical shape of the diameter 

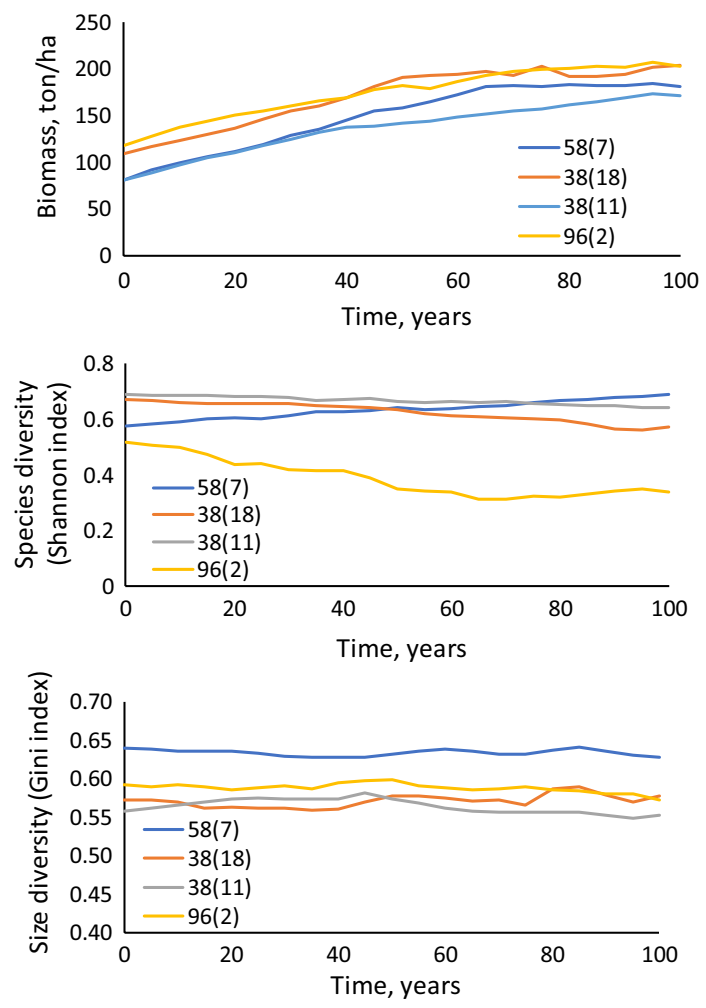

Fig. 1 Development of biomass, Shannon index and Gini index in four larch-birch plots without cuttings
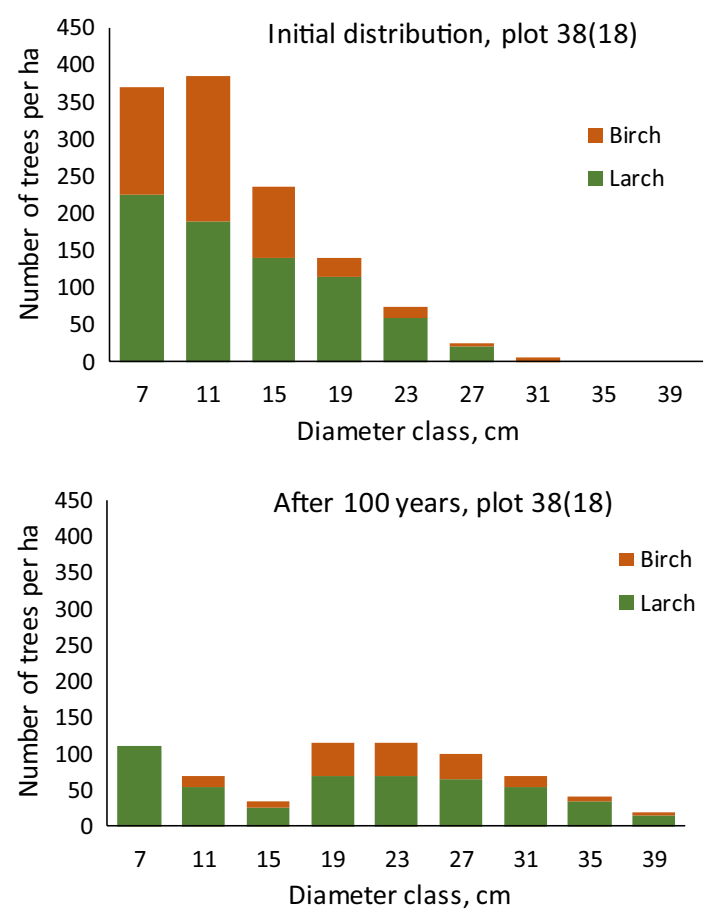

Fig. 2 Initial and final diameter distribution in 100-year simulation of one sample plot distribution of an uneven-aged stand (reversed $J$ ) was lost because of low ingrowth rate due to too high stand density. If the management objective is to convert the stands into uneven-aged mixed stands, the no-cutting schedules may not represent the optimal management.

\section{Management for maximal net present value}

When NPV was maximized without any constraints, it was optimal to conduct a heavy thinning immediately in every plot (Fig. 3 top). The lowest basal areas of the transformation period were as low as $3-5 \mathrm{~m}^{2} \mathrm{ha}^{-1}$. Many cuttings were close to clear-felling, and the schedules may not be considered to represent continuous cover management. The value of Gini index increased in most cuttings, after which it started to decrease. Species diversity was close to the maximum possible value (0.693) for long time periods in most plots, but the steady-state forest often had a somewhat decreased species diversity.
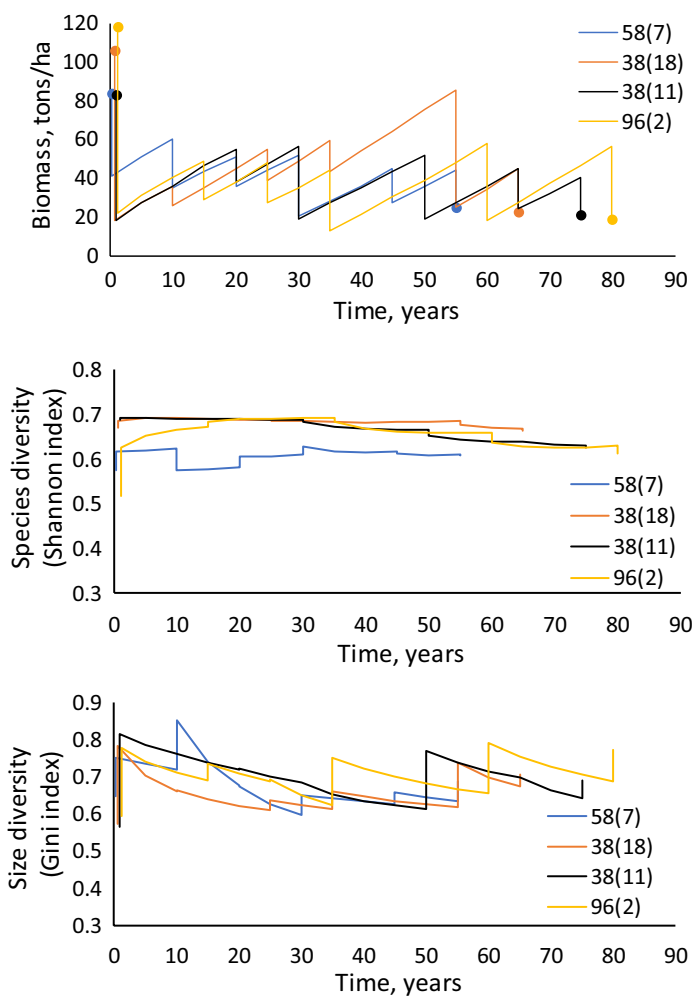

Fig. 3 Development of stand biomass and diversity when five transformation cuttings and the steady-state management are optimized by maximizing the net present value calculated with a $2 \%$ discount rate. The stand development after the fifth cutting represents the cutting cycle of steady-state management, which was assumed to be repeated to infinity 


\section{Optimal management with minimum basal area constraint}

The second set of optimizations maximized NPV with a minimum basal area constraint. In these optimizations, the cuttings were optimized separately for the two species with a constraint that the steady-state distributions had to be sustainable for both species, which means that the species mixture obtained in the fifth transformation could be maintained in all subsequent cuttings. As in the other optimizations,
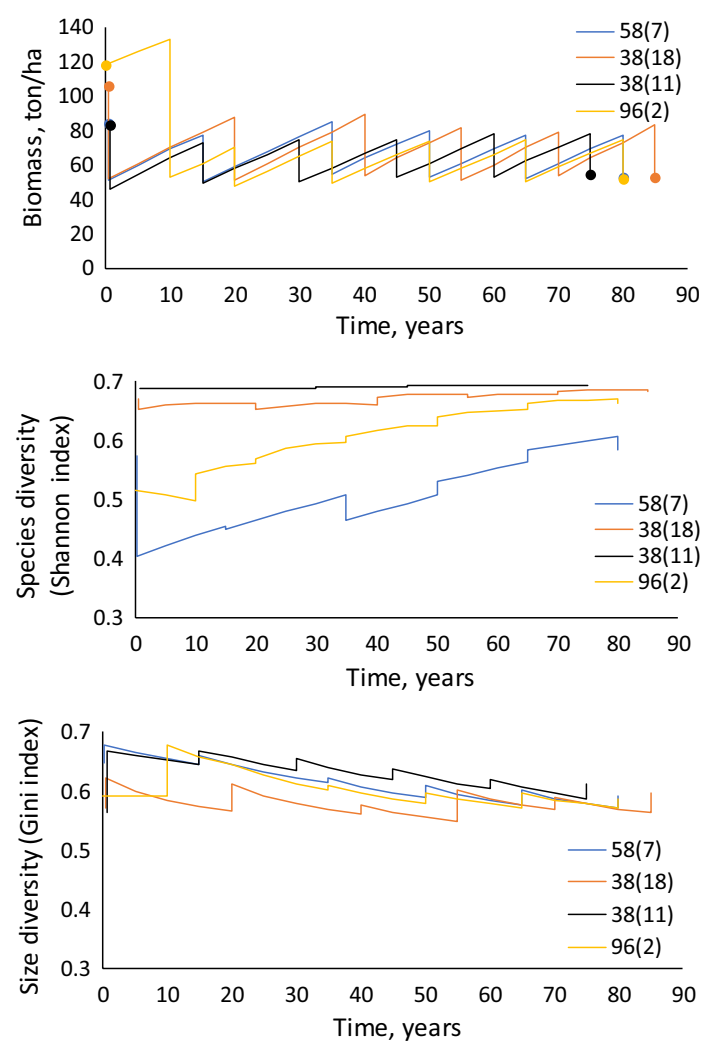

Fig. 4 Stand biomass and diversity in optimal 5-cutting transformation schedule for four plots with a minimum basal area constraint of $10 \mathrm{~m}^{2} \mathrm{ha}^{-1}$. Another constraint of the optimization was set to guarantee that the steady-state management maintains the stand as mixed stand cutting intervals ranged from 10 to 20 years. The cutting interval of the steady-state forest was always 15 years when there was a minimum basal area constraint.

The stand density and biomass decreased from their initial values (Fig. 4). The stand basal area was reduced to almost exactly $10 \mathrm{~m}^{2} \mathrm{ha}^{-1}$ in all cuttings. The stands developed into multi-layered mixed stands with a diameter distribution typical to uneven-aged stands (Fig. 5). Although the stands developed towards the wanted forest structure, the Shannon index indicated that the species mixture of the steady-state stand was not the best possible in the larch-dominated (96(2)) and birch-dominated (58(7)) plots (Figs. 4, 5 left panel).

\section{Constrained multi-objective optimizations}

Multi-objective optimizations were conducted to see whether the stand structure of the steady-state forest could be improved by adding the Shannon and Gini indices to the objective function (Eq. 4). The results showed that the steady-state forest had now more equal amounts of larch and birch, especially in plot 58(7), which was initially dominated by birch (Fig. 5).

The Gini index did not change much, compared to optimizations that maximized NPV with the minimum basal area constraint (Fig. 6). Shannon index improved slightly, especially in the birch-dominated plot (58(7)). Figure 6 shows that the constraint of a minimum basal area of 10 $\mathrm{m}^{2} \mathrm{ha}^{-1}$ decreased NPV. There was no systematic additional decrease in NPV when multi-objective utility function was maximized instead of NPV with the same minimum basal area constraint. The mean annual harvest of the steady-state forest was about $2 \mathrm{~m}^{3} \mathrm{ha}^{-1} \mathrm{a}^{-1}$ in all four plots (Fig. 6).

Figure 7 shows the five transformation cuttings of the birch- and larch-dominated plots in optimizations that maximized multi-objective utility function. The sequences of diameter distributions show how a secondary forest, which was not always typical uneven-sized forest, can be gradually converted into multi-layered mixed steady-state stands, able to maintain their stand structure also in the future.
Fig. 5 Steady-state diameter distribution of the birch-dominated stand when net present value was maximized with minimum basal area constraint (left) or multi-objective utility function was maximized with minimum basal area constraint (right)
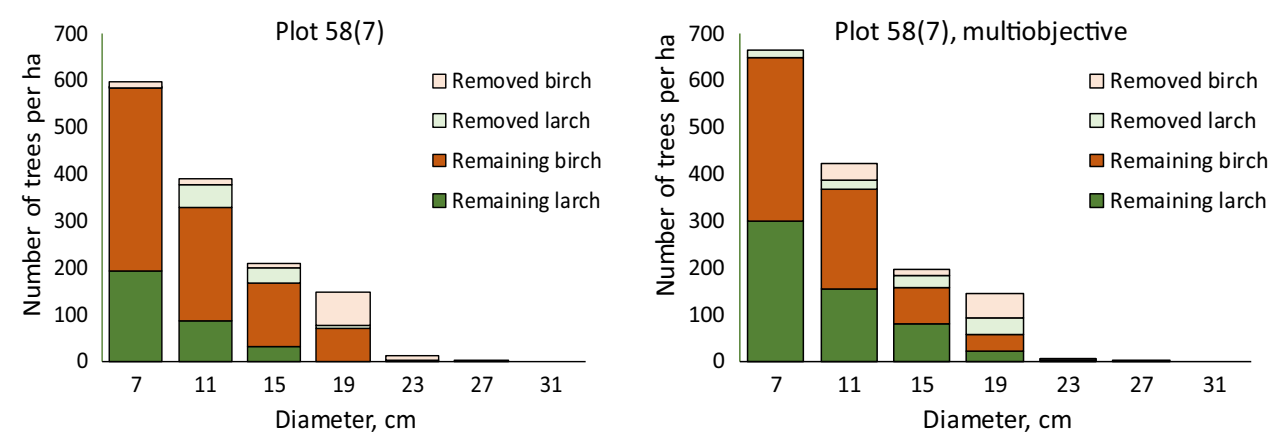

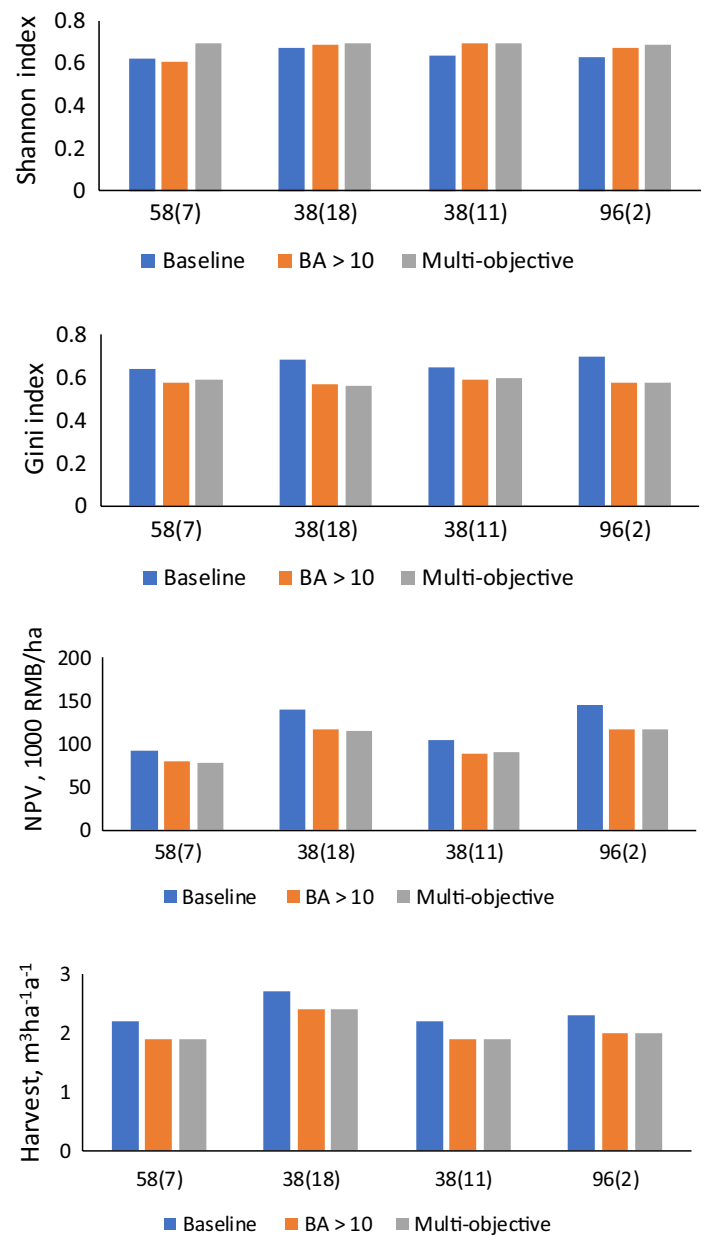

Fig. 6 NPV of the cutting schedule and Shannon and Gini indices and mean annual harvest of the steady-state stand in different optimizations. Baseline problems maximized NPV without any constraints, "BA $>10$ " optimization maximized NPV with minimum basal area constraint, and multi-objective optimization simultaneously maximized NPV, Shannon index and Gini index

\section{Discussion}

This study was the first that optimized the management of uneven-aged forests at the stand level in China. The problem formulation corresponded to the equilibrium endpoint specification, where the transformation cuttings and the structure and management of the steady-state forest were optimized simultaneously. The conversion cuttings of mixed stands were optimized in such a way that the ending forest was sustainable for both species separately, which means that the mixture could be maintained in all subsequent cuttings. As a difference to some previous studies (e.g. Rämö and Tahvonen 2015), the intervals between the transformation cuttings were also optimized, as well as the length of the cutting cycle of the steady-state forest. The number of transformation cuttings was quite high (5), as a too short period may cause economic losses and force the solutions to converge to suboptimal stand structure (Rämö and Tahvonen 2015).

Transformation cuttings of mixed stands with the equilibrium endpoint requirement have been optimized earlier. For example, Bayat et al. (2013) optimized the transformation cuttings of mixed hardwood forests of Hyrcania. However, their problem formulation did not optimize the cutting intensities separately for different species, and their results do not guarantee that the steady-state forest is sustainable in terms of species composition. Pukkala et al. (2014) optimized a sequence of cuttings in the continuous cover management of 200 different stands, many of which were mixed. A part of the optimizations was conducted in such a way that the harvest intensities were optimized separately for different species. The net present value of the optimized management schedule increased slightly, compared to optimizations where the same harvest intensity was used for all species. A sequence of cuttings was optimized without the requirement that the stand structure obtained in the last optimized cutting must represent sustainable steady-state stand structure.

Trasobares and Pukkala (2005) developed so-called investment-efficient optimal stand structures (Buongiorno 2001) for mixed stands of Pinus nigra and Pinus sylvestris. The stand structure was optimized directly, i.e. without optimizing a sequence of cuttings starting from a certain initial stand. The optimal species composition was a consequence of maximized management objective. Sustainable species composition was targeted through constraints or objective variables. Additional optimizations with biodiversity-related management objectives were conducted by penalizing the solution if the stand did not have a continuous presence of large trees.

The results of the current study showed that letting a secondary forest of larch and birch to grow without any management does not result in typical multi-layered uneven-aged stands since too high stand density would decrease regeneration and ingrowth. The no-management option maximizes carbon sequestration into living forest biomass. However, it may not result in optimal stand structure in terms of soil protection. The grass and herb vegetation may be scanty in a dense stand, making the forest floor vulnerable to surface erosion. If lower canopy layers are missing, raindrops hit the ground at high speed in heavy rains, increasing the risk of soil erosion (Selkimäki et al. 2012).

Managing secondary mountain forests for maximal economic profit leads to heavy cuttings, decreasing the stand density to a very low level. These management schedules would reduce the protective functions of the forests, and they would lead to greatly decreased carbon stocks of living forest biomass. However, economically optimal management leads to high Gini indices of the steady-state forest.

For a continuous maintenance of the multiple functions of the secondary mountain forests of larch and birch, some 
Birch dominated plot 58(7)
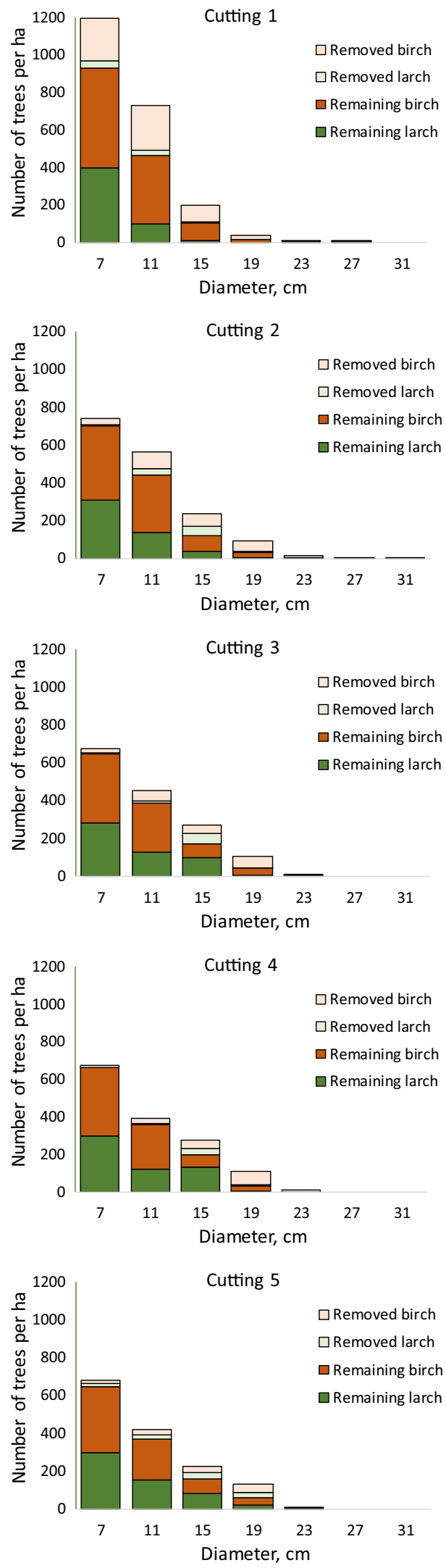

Larch dominated plot 96(2)
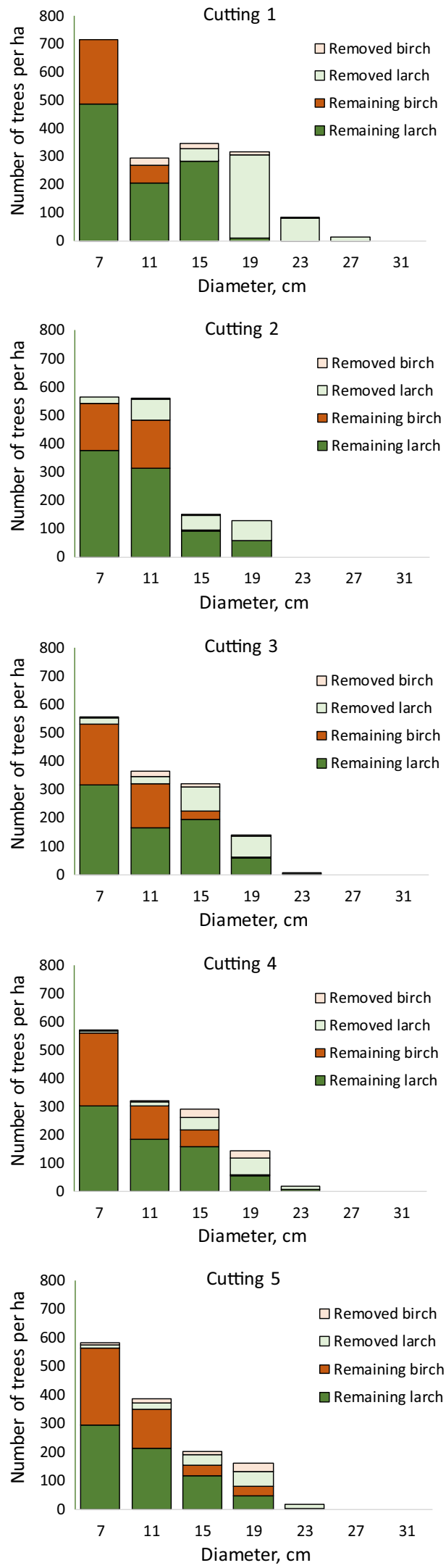

Fig. 7 Optimal transformation cuttings of the birch-dominated and larch-dominated plot 
controlled cuttings might be worthwhile, since they enhance ingrowth and the development of the stands towards a multilayered structure. The study showed that, by a proper management, it would be possible to maintain both the species mixture and uneven-sized vertical structure, making the stands resilient against various hazards.

The data behind the growth models used in this study were collected in similar mixed forests as the initial stands of our optimization. As given in "Appendix 1", the datasets available for modelling were large, and the ranges of variation in, for instance, tree diameter, tree height and stand basal area covered the values simulated for these variables in our optimization cases. Therefore, no extrapolation beyond the ranges of validity of the models was required. However, the effect of species composition on the growth and survival of trees was not explicitly modelled. This could be done in future studies, for instance, in the same way as in Pukkala et al. (2013) where the competition variables such as basal area in larger trees was calculated separately from different tree species, making it possible to describe unequal competitive effects of different species.

Another feature of the used growth models was that site productivity was described with a method developed for even-aged stands. This is not an acceptable approach in uneven-aged forestry since uneven-aged stands do not have any single stand age and the trees from which stand height is measured may have been experienced different periods of suppression at younger age.

However, the initial stands used in our study were secondary forests in which the dominant canopy layer was rather even-aged, and the trees in that layer had developed without suppression by larger trees. Therefore, the method for calculating site productivity was justified. Despite this, there is a need to develop models where site productivity is described using direct site variables, for instance soil type, elevation, aspect, slope and latitude (Trasobares and Pukkala 2004), meteorological variables (Pukkala et al. 2013; Trasobares et al. 2016) or measured past growth of sample trees (Trasobares and Pukkala 2004).

Acknowledgements Open access funding provided by University of Eastern Finland (UEF) including Kuopio University Hospital. This research was financially supported by the National Key Point Research and Development Program of China (No. 2017YFC0504103) and the Fundamental Research Funds for the Central Universities of the People's Republic of China (2572017CA04).

Open Access This article is distributed under the terms of the Creative Commons Attribution 4.0 International License (http://creativeco mmons.org/licenses/by/4.0/), which permits unrestricted use, distribution, and reproduction in any medium, provided you give appropriate credit to the original author(s) and the source, provide a link to the Creative Commons license, and indicate if changes were made.

\section{Appendix 1: Models used in simulation}

Stand development and cuttings were simulated as follows:

1. Calculate site index from the mean tree age $\left(T_{\text {plot }}\right)$ and mean height $\left(H_{\text {plot }}\right)$ of the sample plot

2. Calculate tree height, assortment volumes and biomass using the models shown below

3. Calculate stand characteristics (basal area, volume, total biomass, diversity indices, etc.)

4. Simulate stand development until the next cutting in 5-year steps:

- Increment tree age by 5 years

- Calculate 5-year diameter growth for every tree and add the growth to the dbh

- Multiply frequencies of trees by their 5-year survival probability

- Add ingrowth trees to the list of trees

- Update tree heights, volumes and biomass

- Calculate stand-level variables

5. Simulate cutting by reducing the frequencies of trees in different diameter classes. Calculate the stumpage value of removed trees

6. Repeat steps 5 and 6 until the last cutting.

The following models were used in simulation: site index models, diameter increment models, survival models, tree height models, ingrowth models, taper models and biomass models.

The site index model was based on 1901 permanent sample plots in which the dominant tree species was larch and 1391 permanent sample plots in which the dominant tree species was birch. The age of larch ranged from 12 to 193 years and the age of birch from 4 to 152 years. The range of dominant height was $5.0-26.5 \mathrm{~m}$ in the larch-dominated plots and $3.0-25.0 \mathrm{~m}$ in the birch-dominated plots. The plots were measured during 1990-2010.

The diameter increment, survival and ingrowth models were based on a set of 3292 permanent sample plots in Daxing'an Mountain measured during 1990-2010. In this dataset, consisting of 34,984 tree-level observations for larch and 22,456 observations for birch, the range of variation was 5.0-75.6 cm in larch dbh, 5.0-57.1 in birch dbh, $0.2-39.6 \mathrm{~m}^{2} \mathrm{ha}^{-1}$ in larch basal area and $0.9-36.5 \mathrm{~m}^{2} \mathrm{ha}^{-1}$ in birch basal area. The mean tree diameter ranged from 6.0 to $29.7 \mathrm{~cm}$. The ingrowth models were based on 3830 measured amounts of ingrowth. 
The tree height model was based on measurements in 821 plots $(15,599$ height measurements for larch and 8350 measurements for birch). The height of larch ranged from 1.3 to $31.3 \mathrm{~m}$ and the height of birch from 1.5 to $24.6 \mathrm{~m}$. The taper models were based on 297 felled trees of larch $(5.4-54.6 \mathrm{~cm}$ in $\mathrm{dbh})$ and 470 felled trees of birch $(5.0-43.4 \mathrm{~cm})$ located in where $d_{1}^{2}$ and $d_{2}^{2}$ are the diameter at breast height in the beginning and at the end of the 5-year period $(\mathrm{cm}), \mathrm{SI}$ is the site index, BAL is the basal area in larger trees $\left(\mathrm{m}^{2} \mathrm{ha}^{-1}\right)$, $\mathrm{SDI}$ is the stand density index and id is the 5-year diameter increment $(\mathrm{cm})$.

The models for 5-year survival probability $(s)$ were

Larch: $s=1 /\left[1+\exp \left\{-\left(2.1189+0.5742 \ln (d)-0.00093 d^{2}-0.0683 \mathrm{BAL} / \ln (d)\right\}\right]\right.$

AUC 0.607

Birch: $s=1 /\left[1+\exp \left\{-\left(1.8618+0.188 \ln (d)-0.00134 d^{2}+0.0172 \mathrm{SI}-0.2123 \mathrm{BAL} / \ln (d)\right\}\right]\right.$

AUC 0.641

natural forests in Daxing' an Mountain. The biomass models were based on 122 trees of larch $(6.5-38.1 \mathrm{~cm})$ and 98 trees of birch $(5.4-33.1 \mathrm{~cm})$ which were harvested and measured for stem, root, branch and foliage biomass in the natural forests of Daxing' an Mountain (Dong et al. 2014, 2015b).

The site index of the sample plot was calculated from

$\mathrm{SI}=H_{\text {plot }} / H\left(T_{\text {plot }}\right) \times H\left(T_{\text {index }}\right)$

where $T_{\text {index }}$ is 100 years for larch and 50 years for birch, $H_{\text {plot }}$ is the mean tree height of the sample plot (m) and $T_{\text {plot }}$ is the mean tree age of the sample plot (years). $H\left(T_{\text {plot }}\right)$ and $H\left(T_{\text {index }}\right)$ are calculated from:

Larch: $H(T)=31.725 \times \exp \left(-6.559 T^{-0.493}\right)$

Birch: $H(T)=39.167 \times \exp \left(-6.718 T^{-0.456}\right)$

The models for individual-tree diameter increment were Larch:

$$
\begin{gathered}
d_{2}^{2}-d_{1}^{2}=y=\exp \left(1.494+0.912 \ln (d)-0.000435 d^{2}\right. \\
\left.+0.0353 \mathrm{SI}-0.0761 \mathrm{BAL} / \ln \left(d_{1}\right)-0.164 \ln (\mathrm{SDI})\right)
\end{gathered}
$$

RMSE $0.902, \quad R^{2} 0.336$

Birch:

$$
\begin{aligned}
& d_{2}^{2}-d_{1}^{2}=y=\exp \left(2.702+1.302 \ln \left(d_{1}\right)\right. \\
& -0.000608 d_{1}^{2}+0.00996 \mathrm{SI} \\
& \left.-0.112 \mathrm{BAL} / \ln \left(d_{1}\right)-0.3267 \ln (\mathrm{SDI})\right) \\
& \text { RMSE } 0.825, \quad R^{2} 0.359 \\
& \mathrm{id}=\sqrt{ }\left(y+d_{1}^{2}\right)-d_{1}
\end{aligned}
$$

The individual-tree height $(h, \mathrm{~m})$ models were:

Larch: $h=1.3+32.176 \times \exp (-17.803 /(d+5.551))$

RMSE 2.004, $R^{2} 0.850$

Birch: $h=1.3+27.628 \times \exp (-11.767 /(d+2.974))$

RMSE $1.470, \quad R^{2} 0.870$

Ingrowth models give the number of trees that pass the 5 -cm limit during a 5-year period. The models for the number of ingrowth trees $\left(I\right.$, trees ha $\left.{ }^{-1}\right)$ were

Larch:

$$
\begin{aligned}
I 7= & 1-\left[1 /\left\{1+\exp \left(-\left(2.689-0.585 \ln \left(N_{\text {spe }}\right)+0.0518 G\right)\right)\right\}\right] \\
& \times\left[3.365+0.299 \ln \left(N_{\text {spe }}\right)-0.0568 G\right]
\end{aligned}
$$

Birch:

$$
\begin{aligned}
I= & 1-\left[1 /\left\{1+\exp \left(-\left(1.929-0.532 \ln \left(N_{\text {spe }}\right)+0.0975 G\right)\right)\right\}\right] \\
& \times\left[4.081+0.317 \ln \left(N_{\text {spe }}\right)-0.124 G\right]
\end{aligned}
$$

where $I$ is the number of ingrowth trees (number of trees $\mathrm{ha}^{-1}$ ), $N_{\text {spe }}$ is the number of trees per hectare of that species for which ingrowth is predicted and $G$ is the stand basal area $\left(\mathrm{m}^{2} \mathrm{ha}^{-1}\right)$. The model consists of two parts: the first indicating the probability that there is ingrowth and the second indicating the number of ingrowth trees in case of ingrowth.

The diameter of ingrowth trees at the end of a 5-year time step $(d, \mathrm{~cm})$ was calculated from

Larch: $d=\exp (1.794-0.0223 \sqrt{ } G)$

Birch: $d=\exp (1.755-0.0138 \sqrt{ } G)$ 
The models for stem taper were

Larch: $d=0.933 D^{0.945} H^{0.0824} X^{0.509 q^{4}-\frac{0.181}{\exp \left(\frac{D}{H}\right)}+0.399-0.543 / D-0.0011 H^{Y}+0.197 X}$

RMSE 1.939, $R^{2} 0.979$

Birch: $d=0.950 D^{0.956} H^{0.0663} X^{0.724 q^{4}-\frac{0.592}{\exp \left(\frac{D}{H}\right)}+0.613 X^{0.1}+0.570 / D-0.0022 H^{Y}+0.0412 X}$

RMSE 1.307, $R^{2} 0.979$

where $d$ is the diameter $(\mathrm{cm})$ at height $h(\mathrm{~m}), D$ is the diameter at breast height $(\mathrm{cm}), H$ is the total tree height (m), $q=h / H, X=\left(1-q^{1 / 3}\right) /\left(1-t^{1 / 3}\right)$ where $t=1.3 / H$ and $Y=\left(1-q^{1 / 3}\right)$. Note that the notation of these equations is different from the other models. (Here $D$ is the breast height diameter and $H$ is the tree height, and $d$ is the stem diameter at height $h$.)

The biomass models were of the following form

$\mathrm{BM}=a d^{b}$

Parameters $a$ and $b$ for different biomass components are shown in the following table:

\begin{tabular}{llllll}
\hline $\begin{array}{l}\text { Biomass com- } \\
\text { ponent }\end{array}$ & \multicolumn{2}{l}{ Larch } & & & Birch \\
\cline { 2 - 3 } \cline { 6 - 6 } & $a$ & $b$ & & $a$ & $b$ \\
\hline Stem & 0.0567 & 2.580 & & 0.0949 & 2.410 \\
Branch & 0.00739 & 2.514 & & 0.00314 & 3.066 \\
Foliage & 0.0144 & 1.878 & & 0.00255 & 2.587 \\
Roots & 0.0136 & 2.761 & & 0.0522 & 2.263 \\
\hline
\end{tabular}

The RMSEs of the biomass models were $0.12-0.35$, and the $R^{2}$ values were $0.865-0.989$

\section{Appendix 2: Particle swarm optimization}

Particle swarm optimization (PSO) operates with a population of solution vectors, which are called particles. A particle $\mathbf{x}_{i}$ is a list of values of optimized variables. The initial population of particles was generated by drawing uniformly distributed random numbers from a range defined for each optimized variable. Then, the management schedule was simulated with each solution vector (particle) and the obtained net present value or utility index was used as a measure of the quality of the particle.

In the PSO algorithm, all solution vectors are updated for many iterations. Every particle has an associated vector of velocities $\left(\mathbf{v}_{i}\right)$, which tell how much different elements of the solution vector are changed when $\mathbf{x}_{i}$ is updated. In addition, the best solution vector found so far by particle $i$ $\left(\mathbf{x}_{i}^{\mathrm{b}}\right.$, "particle best") is kept in the memory since it affects the movement of the particle. The movement also depends on the best solution found so far by all particles. This solution is called as "global best" and denoted as $\mathbf{x}^{\mathrm{g}}$.

In this study, all initial velocities were zeros. The velocities and locations of particles were updated as follows:

$\mathbf{v}_{i}^{\text {updated }}=w \mathbf{v}_{i}+c_{1} r_{1}\left(\mathbf{x}_{i}^{b}-\mathbf{x}_{i}\right)+c_{2} r_{2}\left(\mathbf{x}^{g}-\mathbf{x}_{i}\right)$

$\mathbf{x}_{i}^{\text {updated }}=\mathbf{x}_{i}+\mathbf{v}_{i}$

where $w$ is the inertial constant, $c_{1}$ and $c_{2}$ are the parameters that determine how much the particle is directed towards its own best-so-far solution $\left(\mathbf{x}_{i}^{\mathrm{b}}\right)$ and the global best solution $\left(\mathbf{x}^{\mathrm{g}}\right)$, and $r_{1}$ and $r_{2}$ are random numbers uniformly distributed between 0 and 1 .

The PSO parameters used in this study were: population size 30; number of iterations 100; inertial constant $(w) 0.95$; effect of particle best on particle's movement $\left(c_{1}\right) 2.0$; effect of global best on particle's movement $\left(c_{2}\right)$ 2.0.

\section{References}

Adams DM, Ek AR (1974) Optimizing the management of unevenaged forest stands. Can J For Res 4(3):274-287. https://doi. org/10.1139/x74-041

Bayat M, Pukkala T, Namiranian M, Zobeiri M (2013) Productivity and optimal management of the uneven-aged hardwood forests of Hyrcania. Eur J For Res 132(5):851-864

Bettinger P, Tang M (2015) Tree-level harvest optimization for structure-based forest management based on the species mingling index. Forests 6(4):1121-1144

Bettinger P, Graetz D, Sessions J (2005) A density-dependent stand-level optimization approach for deriving management prescriptions for interior northwest (USA) landscapes. For Ecol Manag 217:171-186

Buongiorno J (2001) Quantifying the implications of transformation from even to uneven-aged forest stands. For Ecol Manag 151:121-132

Buongiorno J, Halvorsen EA, Bollandsas OM, Gobakken T, Hofstad O (2012) Optimizing management regimes for carbon storage and other benefits in uneven-aged stands dominated by Norway spruce, with a derivation of economic supply of carbon storage. Scand J For Res 27(5):460-473. https://doi.org/10.1080/02827 581.2012.657671

Dong L, Li F (2016) Additive stand-level biomass models for natural larch forest in the east of Daxing' an mountains. Sci Silvae Sin 52(7):13-20. https://doi.org/10.11707/j.1001-7488.20160702

Dong L, Zhang L, Li F (2014) A compatible system of biomass equations for three conifer species in Northeast, China. For Ecol Manag 329:306-317 
Dong L, Zhang L, Li F (2015a) Developing additive systems of biomass equations for nine hardwood species in Northeast China. Trees 29(4):1149-1163

Dong L, Bettinger P, Liu Z, Qin H (2015b) Spatial forest harvest scheduling for areas involving carbon and timber management goals. Forests 6:1362-1379

Dong L, Bettinger P, Qin H, Liu Z (2018) Reflections on the number of independent solutions for forest spatial harvest scheduling problems: a case of simulated annealing. Silva Fenn 52(1):7803. https ://doi.org/10.14214/sf.7803

Haight RG, Getz WM (1987) Fixed and equilibrium endpoint problems in uneven-aged stand management. For Sci 33:903-931

Haight RG, Monserud WM (1990a) Optimizing any-aged management of mixed-species stands. I. Performance of a coordinate-search process. Can J For Res 20(1):15-25. https://doi.org/10.1139/x90-003

Haight RG, Monserud RA (1990b) Optimizing any-aged management of mixed-species stands. II. Effects of decision criteria. For Sci 36:125-144

Haight RG, Brodie JD, Adams DM (1985) Optimizing the sequence of diameter distributions and selection harvests for uneven-aged stands. For Sci 31(2):451-462

Jactel H, Bauhus J, Boberg J, Bonal D, Castagneyrol B, Gardiner B, Gonzalez-Olabarria JR, Koricheva J, Meurisse N, Brockerhoff EG (2017) Tree diversity drives forest stand resistance to natural disturbances. Curr For Rep 3:223-243. https://doi.org/10.1007/ s40725-017-0064-1

Jiang H (2008) Study on hydrological characteristics of forest ecosystem in Daxing' anling. PhD thesis, Northeast Forestry University, Harbin, P. R. China. (in Chinese with English abstract)

Jiang L, Ma Y, Ling A (2016) Variable-exponent taper models for Dahurian Larch in different regions of Daxing'anling. Sci Silvae Sin 52(2):17-25. https://doi.org/10.11707/j.1001-7488.20160203

Jin X, Pukkala T, Li F, Dong L (2017) Optimal management of Korean pine plantations in multifunctional forestry. J For Res 28:1027-1037

Jin X, Pukkala T, Li F (2018) Meta optimization of stand management with population based methods. Can J For Res 28:697-708

Knoke T, Wurm J (2006) Mixed forests and a flexible harvest policy: a problem for conventional risk analysis? Eur J For Res 125:303315. https://doi.org/10.1007/s10342-006-0119-5

Knoke T, Ammer C, Stimm B, Mosandl R (2008) Admixing broadleaved to coniferous tree species: a review on yield, ecological stability and economics. Eur J For Res 127:89-101

Li H, Li F, Jia W, Wang S (2014) Water conservation of litterfall in different mixed forest types of white Birch and Larch in Daxing'an mountain. J Northeast For Univ 42(6):43-52 (In Chinese)

Liu F, Li F, Zhang L, Jin X (2014) Modeling diameter distributions of mixed-species forest stands. Scand J For Res 29(7):653-663

Lüpke B, Spellmann H (1999) Aspects of stability, growth and natural regeneration in mixed Norway spruce-European beech stands as a basis of silviculture decisions. In: Olsthoorn AFM et al (eds) Management of mixed-species forests: silviculture and economics. IBN-DLO Scientific Contributions, Wageningen, pp 245-267

Peng W, Pukkala T, Jin X, Li F (2018) Optimal management of Larix olgensis plantations in northeast China when timber production and carbon stock are considered. Ann For Sci 75:63. https://doi. org/10.1007/s13595-018-0739-1

Pielou EC (1977) Mathematical ecology. Wiley, Toronto

Pukkala T (2009) Population-based methods in the optimization of stand management. Silva Fenn 43(2):261-274

Pukkala T (2015) Optimizing continuous cover management of boreal forest when timber prices and tree growth are stochastic. For Ecosyst 2(6):1-13

Pukkala T, Lähde E, Laiho O (2013) Species interactions in the dynamics of even- and uneven-aged boreal forests. J Sustain For 32(4):371-403
Pukkala T, Lähde E, Laiho O (2014) Optimizing any-aged management of mixed boreal under residual basal area constraints. J For Res 25(3):627-636

Pukkala T, Laiho O, Lähde E (2016) Continuous cover management reduces wind damage. For Ecol Manage 372:120-127

Rämö J, Tahvonen O (2014) Economics of harvesting uneven-aged forest stands in Fennoscandia. Scand J For Res 29(8):777-792. https://doi.org/10.1080/02827581.2014.982166

Rämö J, Tahvonen O (2015) Economics of harvesting boreal unevenaged mixed-species forests. Can J For Res 45:1102-1112. https:// doi.org/10.1139/cjfr-2014-0552

Sanchez Orois S, Chang SJ, Kv Gadow (2004) Optimal residual growing stock and cutting cycle in mixed uneven-aged maritime pine stands in Northwestern Spain. For Pol Econ 6:145-152

Selkimäki M, Gonzaléz-Olabarria JR, Pukkala T (2012) Site and stand characteristics related to surface erosion occurrence in forests of Catalonia (Spain). Eur J For Res 131:727-738

Shi F, Zu Y, Suzuki K, Yamaoto S, Nomura M, Sasa K (2000) Effects of site preparation on the regeneration of larch dominant forests after a forest fire in the Daxinganling mountain region, northeast China. Eurasian J For Res 1:11-17

State Development Planning Commission and State Forestry Bureau (2010) The ecological protection and economic transformation plans of Great Xing' an Mountain in 2010-2020. Chinese Forestry Press, Beijing (in Chinese)

State Forestry Administration (2014) The eighth forest resource survey report. http://211.167.243.162:8085/8/index.html. Accessed 5 Nov 2018

State Forestry Bureau (2005) Code of forest harvesting in China (LY/ T1646-2005). State Forestry Bureau, Beijing (in Chinese)

State Forestry Bureau (2014) Forest resources statistics of China for 2009-2013. Chinese Forestry Press, Beijing (in Chinese)

Sterba H (2004) Equilibrium curves and growth models to deal with forests in transition to uneven-aged structure-application in two sample stands. Silva Fenn 38(4):413-423

Sun L, Zhang Y, Guo Q, Hu H (2009) Carbon emission and dynamic of NPP post forest fires in 1987 in Daxing' an mountains. Sci Sylvae Sin 45(12):101-104 (in Chinese)

Thompson I, Mackey B, McNulty S, Mosseler A (2009) Forest resilience, biodiversity, and climate change. A synthesis of the biodiversity/resilience/stability relationship in forest ecosystems. Secretariat of the Convention on Biological Diversity, Montreal. Technical series no 43, $67 \mathrm{pp}$

Trasobares A, Pukkala T (2004) Using past growth to improve individual-tree diameter growth models for uneven-aged mixtures of Pinus sylvestris L. and Pinus nigra Arn. in Catalonia, north-east Spain. Ann For Sci 61(5):409-417

Trasobares A, Pukkala T (2005) Optimising the management of uneven-aged Pinus sylvestris L. and Pinus nigra Arn. mixed stands in Catalonia, north-east Spain. Ann For Sci 61:747-758

Trasobares A, Zingg A, Walthert L, Bigler C (2016) A climate-sensitive empirical growth and yield model for forest management planning of even-aged beech stands Eur. J For Res 135(2):263282. https://doi.org/10.1007/s10342-015-0934-7

Valbuena R, Packalén P, Martín-Fernández S, Maltamo M (2012) Diversity and equitability ordering profiles applied to study forest structure. For Ecol Manag 276:185-195

Wikström P (2000) A solution method for uneven-aged management applied to Norway spruce. For Sci 46(3):452-463

Publisher's Note Springer Nature remains neutral with regard to jurisdictional claims in published maps and institutional affiliations. 